A COMPARATIVE STUDY OF THE ROTATORY AND REDUCING PROPERTIES OF ULTRAFILTRATES FROM

\title{
BLOOD PLASMA
}

\author{
By JOHN R. PAUL 1 \\ (From the John Herr Musser Department of Research Medicine, University of Pennsylvania, \\ and the Ayer Clinical Laboratory, Pennsylvania Hospital, Philadelphia)
}

(Received for publication August 13, 1926)

Attempts to measure and define the nature of blood sugar present certain difficulties largely because the more familiar methods at our disposal are dependent upon certain properties which substances other than glucose may also exhibit. Reducing power, optical activity and the property of being fermented, notably by yeast, represent the most important of these properties. The well known reducing methods employed for blood sugar estimation are apparently sufficiently accurate for general clinical purposes, but it is recognized that there may be small amounts of reducing substances in the blood which cannot be attributed to glucose. The exact nature of these has not been accurately defined, although it is known that uric acid, creatinine, creatine, glucuronic acid, pentoses, disaccharides, purines and adrenalin have the power of reducing the reagents commonly used in blood sugar determinations. Hiller, Linder and Van Slyke (1) have recently studied the other reducing substances in blood and in a series of reducing determinations both before and after the removal of the glucose by yeast fermentation and by the glycolytic action of blood they found that the residue of reducing substance was equivalent to 0.01 to 0.03 per cent of glucose.

The use of the polariscope for the estimation of blood sugar may be subjected to similar criticism, owing to the presence of other optically active substances, although this fact does not seem to have been emphasized in recent work on the specific rotation of the glucose of normal blood (12) (19). The literature covering the general subject

${ }^{1}$ Robert Robinson Porter Fellow in Research Medicine, University of Pennsylvania. 
of the rotatory properties of blood is by no means as voluminous as that covering its reducing properties but many comparative polariscopic and reducing studies have been made and the results have seemed to be of sufficient importance to warrant a brief review.

In 1901 Paul Mayer (2) in a comparative study of the rotatory and reducing values of filtrates of animal and human blood, noted that the discrepancies between the two were appreciable. He attributed this difference largely to the presence of levorotatory substances which he succeeded in demonstrating after removing the sugar by fermentation and concluded that glucuronic acid, probably present in the conjugated state, was responsible for this levorotation and represented a normal constituent of the circulating blood.

These findings were in large measure confirmed and also amplified by the work of Lepine and Boulud (3), who in a series of studies on animal blood, found that conjugated glucuronic acid was always present and that it was increased in amount if the blood was allowed to stand, particularly if the glycolytic action of whole blood was not prevented. These investigators suspected that the relation between glucose and glucuronic acid formation was intimately associated with the problem of glucose metabolism.

In 1908 Michaelis and Rona (4) dialyzed blood plasma against a series of glucose solutions of varied concentration of which some were approximately isotonic with the estimated glucose content of blood. The dialysates were studied by polarimetric and reducing methods. It is somewhat difficult to interpret their results as to agreement between rotatory and reducing power of the actual blood sugar, but in general, fairly close agreement between the rotatory and reducing values of the dialysates was noted. In a later study, however, on protein-free blood filtrates Rona and Takahashi (5) compared the rotatory value of the filtrates before and after fermentation and noted the occasional presence of traces of levorotatory substances.

Similarly Oppler (6), working with blood filtrates in which the protein had been precipitated with phosphotungstic acid, made a series of comparative studies on blood sugar by reducing, polariscopic and fermentation methods. He obtained fairly close agreement between the rotatory and reducing values of these filtrates but found in some instances (about 40 per cent) that the rotatory values were lower than the reducing values. He attributed these discrepancies to the presence of levorotatory substances and although he did not define these substances he suggested that they were probably acid in nature, and probably analogous to those found in urine. In concluding he stated that these substances should be considered as sources of error in any method which attempts to estimate blood sugar by the use of the polariscope.

In a later study on the rotatory value of protein free blood filtrates, Lyttkens and Sandgren (7), noted that the presence of other optically active substances in these filtrates distinctly interferes with the accuracy of this method for the estimation of blood sugar. 
On the other hand Griesbach and Strassner (8) obtained fairly close agreement in their comparative study of the rotatory and reducing values of blood filtrates and concluded that the polariscopic method was a practical one for the estimation of blood sugar. Fairly close agreement between rotatory and reducing values was also reported by Maase and Tachau (9).

In a more recent and rather comprehensive study Stepp $(10,11)$ has discussed the variables which enter into the problem of blood sugar estimation. He has placed particular emphasis upon the error in the reducing methods brought about by the presence of other reducing substances such as uric acid, creatinine, creatine, amino acids, etc., as well as similar errors in rotatory determinations caused by the presence of $\beta$-oxybutyric acid, amino acids and glucuronic acids, particularly the latter. In his experimental data on blood filtrates, fairly close agreement between rotatory and fermentation values, were obtained, but as a rule the rotatory values proved to be lower than the reducing values, by about 20 to 30 per cent. He also noted that in the course of concentrating the blood filtrates there was a fall in the initial reducing values so that they approached the rotatory ones and from these observations he concluded that certain volatile reducing substances might be present. His observations were extended to include studies on the blood of nephritics and diabetics and he reported that in diabetes the higher the blood sugar, the greater was the difference between reduction and rotation.

A somewhat different interpretation of the differences between rotatory and reducing values in the blood of normal individuals and in diabetics was introduced in 1923 by the work of Winter and Smith (12). These investigators precipitated the protein from samples of human and animal blood by the method of Folin and $\mathrm{Wu}$. The resulting filtrate, after concentration by vacuum distillation at $40^{\circ} \mathrm{C}$. was then reprecipitated with alcohol in order to remove existing traces of protein and reconcentrated; a process which under favorable circumstances required about 6 hours. On comparing the rotatory value of the final protein-free extract with the reducing value, they found that in normal individuals the initial rotatory values were well below those of the reducing values but rose on standing until in the course of a few days they were practically equal to the reducing values. They concluded that these low rotatory values might indicate the presence in normal blood of a type of glucose which was not the stable $\alpha, \beta$-glucose, but a less stable variety such as that identified by Irvine and his coworkers and styled $\gamma$-glucose. They further suggested that the transformation of $\alpha, \beta$-glucose into $\gamma$-glucose might represent an important preliminary step in the preparation of glucose for utilization by the body.

Considerable doubt has been cast upon the conclusions drawn by Winter and Smith by Hewit (13), and by Eadie (14). The latter repeated the work and obtained not only polarimetric readings similar to those reported by Winter and Smith for normal blood but also others of an exactly opposite character. Eadie is quoted by Macleod (15) as having shown that in extracts of normal blood polarimetric readings are often obtained which are less dextrorotatory than they should 
be, as judged by the reducing power, and which slowly become greater on standing but that this, instead of indicating an increase in the specific rotation of the glucose present, may depend upon the presence of glucosides which gradually become hydrolyzed on standing, or of traces of other levorotatory substances which are gradually destroyed.

Van Creveld (16) also repeated in some measure Winter and Smith's work, but eventually abandoned the lengthy methods of deproteinization of blood as advocated by Winter and Smith, choosing instead to work with the aqueous humor of the eye, serum ultra-filtrates and artificially produced transudates. With the aqueous humor he noted that reduction and optical rotation determinations showed close agreement and mutarotation could not be detected. With serum ultrafiltrates and transudates no changes were noted in rotation, but there was always a small difference between rotation and reduction with the reducing values slightly less than the rotatory ones.

Later Denis and Hume (17) repeated the experiments of Winter and Smith and found that the percentage of glucose in the blood extracts was invariably higher when determined by reduction than when calculated from rotation. They also attributed this to the presence in the blood, of substances other than glucose which were responsible for a part of the optical rotation and of the reducing power of deproteinized extracts. In fact, similar discrepancies between rotatory and reducing values were observed by these investigators with "synthetic" blood extracts prepared from glucose, salts and nitrogenous extractives which were subjected to a distillation and extraction process exactly similar to the one used on blood.

Quite recently Visscher (18) has reported an interesting study on the rotatory properties of a series of human and animal blood filtrates including a repetition of the procedure followed by Winter and Smith. He found that the initial rotatory values of blood filtrates in which protein precipitation had been carried out by the Folin and $\mathrm{Wu}$ method were below the reducing values and in one instance an initial levorotatory value was observed. On standing this rotatory value rose somewhat irregularly in the course of a few days, to be followed by a rapid fall. By using different protein precipitants he obtained somewhat different initial rotatory values and on standing different fluctuations. His experiments did not suggest that the findings were due to the presence of a relatively unstable form of glucose which gradually reverted to the more stable form, but rather that substances other than glucose, were influencing these values.

However, Lundsgaard and Holbøll (19) have again raised the question as to whether the discrepancies between rotatory and reducing values in the blood of normal individuals may not indicate changes in specific rotation of the glucose present. They employed a different method in order to obtain a protein free extract of blood which would be suitable for polariscopic study. This consisted of dialyzing samples of blood, to which 2 per cent sodium fluoride had been added to prevent coagulation and glycolysis, against 0.9 per cent solutions of $\mathrm{NaCl}$ for a 
period of $1 \frac{1}{2}$ hours and studying the dialysates thus obtained. These investigators noted that in normal individuals the rotatory values expressed in terms of glucose, were considerably lower than the reducing values if the determination was made on the same day that the blood sample was obtained. At the end of 48 hours, however, the rotatory values were found to have risen until they were practically in agreement with the reducing values. In diabetic individuals, on the other hand, the rotatory and reducing values were found to show remarkably close immediate agreement. On the basis of these findings they suggested that the blood sugar of normal individuals might have a lower specific rotation than that of glucose although it eventually reverted to $\alpha, \beta$-glucose on standing. This interpretation is in accord with the "new glucose" theory that these authors have previously formulated (20), which suggests that insulin together with other substances may have a direct action upon the sugar molecule in preparing it for utilization by the body.

Since submitting this article for publication my attention has been called to a recent paper by Anderson and Carruthers (26) on the relation between optical activity and reducing power of normal blood filtrates in which the views proposed by Lundsgaard and Holb $\phi 11$ have been critically reviewed. These investigators employing concentrated ultrafiltrates, dialysates and alcohol extracts of plasma observed that the rotatory power of these solutions was low as compared to its reducing power. They did not note any fluctuations of the rotatory values on standing but they did note that reversible changes in these rotatory values were brought about by altering the $\mathrm{pH}$ of the solutions. It was suggested that these results were due to the presence in plasma of one or more optically active substances other than glucose. Laked corpuscles were shown by these authors to yield strongly levorotatory ultrafiltrates which have little reducing power.

The review of the literature given above may be summarized by the statement that the majority of investigators who have studied the rotatory values of blood have found somewhat irregular and inconstant differences between these values and the reducing values and most investigators have attributed these differences to the presence of optically active and reducing substances other than glucose. A number of rather divergent views have, however, been expressed with regard to the significance and relationship which these differences may have to the question of glucose metabolism; notably the early views of Lepine, who attributed these differences largely to the presence of glucuronic acid and who emphasized the importance which conjugated glucuronic acid might play as a product of glucose metabolism. Again we have the significance of these differences in rotatory and reducing values viewed from another angle in which they are not 
attributed to the actual presence of optically active substances other than glucose but rather to the possibility that the specific rotation of the glucose in normal blood may be lower than that of $\alpha, \beta$-glucose. It has been suggested that this altered glucose may be a less stable form such as $\gamma$-glucose, or Lundsgaard's and Holbøll's "new glucose," and may represent one of the normal stages through which $\alpha, \beta$-glucose is prepared for utilization by the body.

Unquestionably, the relationship which the rotatory power has to the actual glucose content of blood and its bearing upon the question of glucose metabolism would seem to warrant a great deal of further study. The series of experiments recorded below deals only with the question from one angle, namely, an attempt to define the limits of the differences between rotatory and reducing values in blood plasma in normal individuals; to record the fluctuation of the rotatory values of a given specimen over a period of several days and finally to study the rotatory power of plasma after the sugar has been removed by the glycolytic action of whole blood. It is not within the scope of this paper to define the nature of the optically active substances, other than glucose or to discuss their relationship to glucose metabolism.

\section{METHODS}

The measurement of the rotatory value of normal blood offers difficulties owing to the fact that the physiological concentration of optically active substances is small. Hence accuracy is limited, unless the amount of blood filtrate obtained is large, so that a long polariscope tube may be filled. Such large quantities of blood as are required for these determinations are not always easy to procure from human beings. In selecting a method for obtaining a protein free extract of blood which would be suitable for polariscopic study, the use of collodion membranes as employed by Lundsgaard and Holbøll for the separation of the blood electrolytes from the protein was considered the most satisfactory. The methods of precipitation of the blood protein, filtration and concentration of the filtrate used by other investigators were rejected on account of the length of the process and because of the introduction of variable factors. Instead of using blood dialysates, however, such as were studied by Lundsgaard and Holbøll, ultrafiltrates from the collodion sacs were employed. This method has advantages in that an extract of blood can be obtained in which the resulting glucose concentration in the filtrate more nearly approaches that of the blood plasma. The higher concentration tends to increase the accuracy of the determinations and the dilution factor is eliminated.

The collodion sacs were prepared from a 7 per cent solution of Du Pont's par- 
lodion dissolved in a solution of 75 per cent by volume of ether and 25 per cent of absolute alcohol. In the preliminary experiments on the preparation of suitable collodion membranes the principles emphasized by Eggerth (21) were followed. The standard eventually adopted was that the sacs should be impermeable to hemoglobin but easily permeable to glucose, In making a sac, the inside of a test tube was coated with collodion, drained and allowed to dry for about 4 or 5 minutes until the collodion was quite firm. The tube was then filled to the brim with 70

TABLE 1

Showing the error encountered in 15 reducing and rotary determinations on a series of standard glucose solutions of graded values*

\begin{tabular}{c|c|c|c|c|c}
\hline $\begin{array}{c}\text { Calculated } \\
\text { values }\end{array}$ & $\begin{array}{c}\text { Reducing } \\
\text { values } \\
\text { (Folin and Wu) }\end{array}$ & $\begin{array}{c}\text { Difference } \\
\text { between } \\
\text { reducing and } \\
\text { calculated } \\
\text { values }\end{array}$ & Rotatory values & $\begin{array}{c}\text { Difference } \\
\text { between rotatory } \\
\text { and calculated } \\
\text { value }\end{array}$ & $\begin{array}{c}\text { Difference } \\
\text { between rotatory } \\
\text { and reducing } \\
\text { value }\end{array}$ \\
\hline gram per 100 cc. & gram per 100 cc. & gram per 100 cc. & gram per 100 cc. & gram per 100 cc. & gram per 100 cc. \\
0.150 & 0.148 & -0.002 & 0.149 & -0.001 & 0.001 \\
0.140 & 0.138 & -0.002 & 0.147 & +0.007 & 0.009 \\
0.130 & 0.131 & +0.001 & 0.126 & -0.004 & 0.005 \\
0.120 & 0.120 & 0.000 & 0.110 & -0.010 & 0.010 \\
0.110 & 0.109 & -0.001 & 0.124 & +0.014 & 0.015 \\
0.100 & 0.099 & -0.001 & 0.096 & -0.004 & 0.003 \\
0.090 & 0.092 & +0.002 & 0.102 & +0.012 & 0.010 \\
0.080 & 0.080 & 0.000 & 0.076 & -0.004 & 0.004 \\
0.070 & 0.068 & -0.002 & 0.075 & +0.005 & 0.007 \\
0.060 & 0.057 & -0.003 & 0.068 & +0.008 & 0.009 \\
0.050 & 0.055 & +0.005 & 0.066 & +0.016 & 0.011 \\
0.040 & 0.038 & -0.002 & 0.041 & +0.001 & 0.003 \\
0.030 & 0.026 & -0.004 & 0.035 & +0.005 & 0.009 \\
0.020 & 0.018 & -0.002 & 0.020 & 0.000 & 0.002 \\
0.010 & & & 0.008 & -0.002 & \\
\hline Max. Dif............. & 0.005 & & 0.016 & 0.015 \\
Av. Dif................ & 0.002 & & 0.007 & 0.007 \\
\hline
\end{tabular}

* All of the values are expressed in grams of glucose per $100 \mathrm{cc}$.

per cent alcohol and allowed to stand for 20 minutes. Distilled water was then substituted for the alcohol for a period of 1 hour. At the end of this time the sac was usually found to have contracted slightly from the tube wall and could be drawn out with relative ease. The sacs were then tested for leaks and impermeability to hemoglobin by filling them with a solution of hemoglobin and subjecting them to a negative pressure of $200 \mathrm{~mm}$. of mercury. The selected ones were kept in water to which a few crystals of thymol had been added and were used repeatedly over a period of about 3 to 4 weeks. The method of ultrafiltration was that described by Marshall and Vickers (22). 
Polariscopic readings were made with a Reichert instrument, using a $189 \mathrm{~mm}$. tube with a Mazda lamp with a dichromate solution filter as the source of light. The value of $+52.8^{\circ}$ was taken for the specific rotation of glucose. In every instance the average of a series of at least 15 readings was determined, together with a series of readings of the zero point.

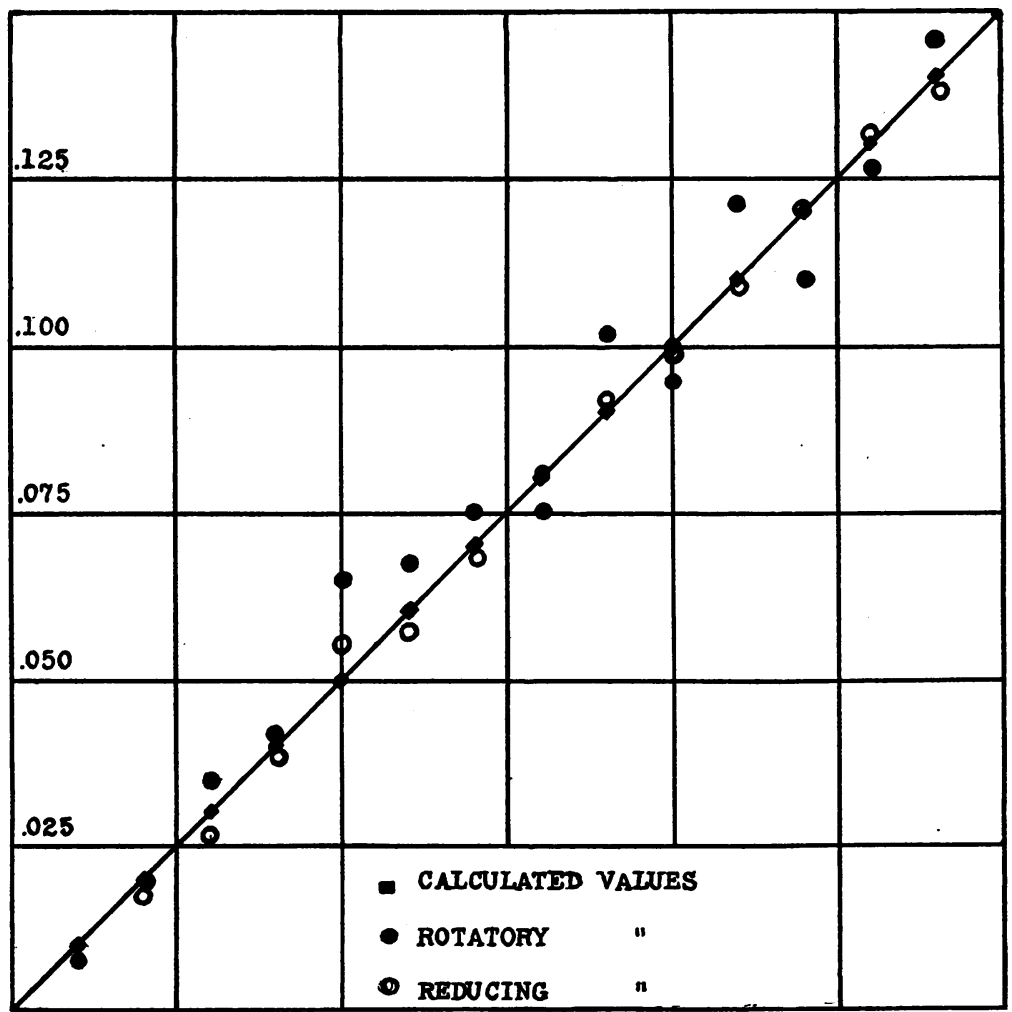

Fig. 1. Reducing and Rotatory Determinations on a Series of Standard Glucose Solutions of Graded Values, Ranging from 0.010 TO 0.150 GRAM OF GLUCOSE PER $100 \mathrm{cC}$.

For the reducing determination two methods were employed, that of Folin and $\mathrm{Wu}$ (23) and also that of Hagedorn and Jensen (24).

Blood samples of from 60 to $250 \mathrm{cc}$. were collected from normal individuals, from general hospital patients and, in some instances, from cadavers within 10 to 30 minutes after death. The blood was collected aseptically using sodium citrate and sodium fluoride as anticoagulant and antiglycolytic agents. After collection, the specimen was immediately centrifuged and the cells discarded. 
The plasma was placed in a collodion sac and subjected to a negative pressure of 150 to $200 \mathrm{~mm}$. of mercury for filtration. About 11 or $12 \mathrm{cc}$. of filtrate were necessary for the determinations, as $10 \mathrm{cc}$. were required to fill the polariscope tube and at least $1 \mathrm{cc}$. was used for the initial reducing determination. To procure this amount, from 3 to 5 hours of filtration were generally necessary. Initial rotatory and reducing determinations were done in all instances on the same day on which the specimen was collected. The solution was then left in the polariscope tube which was placed in the ice box for an interval of 2 to 5 days, during which time a series of rotatory readings were made at room temperature. At the end of this time a final reducing determination was made.

For the standardization and the determination of the degree of experimental error which the rotatory and reducing methods employed would show, the following procedure was used. A solution of Merck's pure dextrose was prepared in distilled water and its concentration accurately determined with the polariscope using a $4 \mathrm{dm}$. tube. From this standard a series of 15 graded solutions were prepared by dilution, in which the estimated glucose concentration ranged from 0.150 to 0.010 gram per $100 \mathrm{cc}$., corresponding to the range of glucose concentration which the blood samples included in this series show. The rotatory and reducing determinations made on this series of solutions are shown in table 1 and figure 1 .

The maximum limit of experimental error for both of the reducing methods employed in this experiment had been previously established in a series of determinations on a glucose solution with a concentration of 0.100 gram per $100 \mathrm{cc}$., as 1.7 per cent; the average error being about 1 per cent. The differences between the reducing values and the calculated values of the solutions in this series fall practically within this range in the solutions with concentrations ranging from 0.070 gram to 0.150 gram per $100 \mathrm{cc}$. Below this range, i.e., 0.070 to 0.010 gram, the error becomes greater. It will also be noted that the differences between rotatory and reducing values is considerable showing a maximum difference of 0.015 gram of glucose per $100 \mathrm{cc}$. and an average of 0.007 gram of glucose per $100 \mathrm{cc}$. This error proved to be the same in actual magnitude for any solution of glucose with a concentration within the range of 0.010 to 1.000 gram per $100 \mathrm{cc}$. The experimental results of this paper have been viewed critically from the standpoint of this error and all of the rotatory values are considered as having probable deviations, at least to the extent of \pm 0.007 gram of glucose per $100 \mathrm{cc}$.

\section{EXPERIMENTAL}

A small series of blood samples obtained from normal individuals was first examined to ascertain the relation of the reducing values of the ultrafiltrates to that of the plasma and to the rotatory values of the ultrafiltrates. The degree of fluctuation which the rotatory values exhibited on standing was also studied. The results on 5 such blood samples are given in table 2 . 
From table 2 it will be noted that the reducing values of the ultrafiltrates proved to be consistently higher (averaging about 10 per cent)

TABLE 2

Reducing and rotatory values encountered in 5 normal individuals*

\begin{tabular}{|c|c|c|c|c|c|c|c|c|}
\hline $\begin{array}{c}\text { Experi- } \\
\text { ment } \\
\text { number }\end{array}$ & $\begin{array}{l}\text { Reduc- } \\
\text { ing } \\
\text { value of } \\
\text { plasma }\end{array}$ & $\begin{array}{l}\text { Reducing } \\
\text { value of } \\
\text { ultra- } \\
\text { filtrate }\end{array}$ & $\begin{array}{l}\text { Initial } \\
\text { rotatory } \\
\text { value }\end{array}$ & $\begin{array}{l}24 \text {-hour } \\
\text { rotatory } \\
\text { value }\end{array}$ & $\begin{array}{l}\text { 48-hour } \\
\text { rotatory } \\
\text { value }\end{array}$ & $\begin{array}{l}\text { 72-hour } \\
\text { rotatory } \\
\text { value }\end{array}$ & $\begin{array}{l}96 \text {-hour } \\
\text { rotatory } \\
\text { value }\end{array}$ & $\begin{array}{c}\text { Final } \\
\text { reducing } \\
\text { value }\end{array}$ \\
\hline & $\begin{array}{l}\text { gram per } \\
100 \mathrm{cc} .\end{array}$ & $\begin{array}{l}\text { gram per } \\
100 \mathrm{cc} .\end{array}$ & $\begin{array}{l}\text { gram per } \\
100 \text { cc. }\end{array}$ & $\begin{array}{l}\text { gram per } \\
100 \mathrm{cc} .\end{array}$ & $\begin{array}{l}\text { gram per } \\
100 \text { cc. }\end{array}$ & $\begin{array}{l}\text { gram per } \\
100 \text { cc. }\end{array}$ & $\begin{array}{l}\text { gram per } \\
100 \mathrm{cc} .\end{array}$ & $\begin{array}{c}\text { gram per } \\
100 \mathrm{cc} .\end{array}$ \\
\hline 37 & 0.077 & 0.085 & +0.037 & +0.051 & +0.021 & & & \\
\hline 38 & & & & & & & & 0.109 \\
\hline 40 & 0.084 & 0.086 & -0.031 & -0.003 & +0.031 & +0 . & +0.009 & 0.084 \\
\hline 41 & 0.096 & 0.104 & -0.003 & -0.028 & +0.012 & +0.039 & +0.049 & 0.102 \\
\hline 42 & 0.072 & 0.082 & +0.033 & +0.013 & +0.016 & +0.005 & +0.013 & 0.084 \\
\hline
\end{tabular}

* All of the values are expressed in terms of grams of glucose per $100 \mathrm{cc}$. although the levorotatory values are, of course, arbitrarily represented in such units.

TABLE 3

Reducing and rotatory values encountered in 13 hospital cases

\begin{tabular}{|c|c|c|c|c|c|c|c|}
\hline $\begin{array}{c}\text { Experi- } \\
\text { ment } \\
\text { number }\end{array}$ & Diagnosis & $\begin{array}{c}\text { Post } \\
\text { mortem } \\
\text { collection } \\
\text { of blood }\end{array}$ & $\begin{array}{l}\text { Reduc- } \\
\text { Ing } \\
\text { value of } \\
\text { ultra- } \\
\text { filtrate }\end{array}$ & $\begin{array}{c}\text { Initial } \\
\text { rotatory } \\
\text { value }\end{array}$ & $\begin{array}{c}24 \text {-hour } \\
\text { rotatory } \\
\text { value }\end{array}$ & $\underset{(\mathrm{R}-\mathrm{P})}{\text { Initial }}$ & $\begin{array}{c}\text { 24- } \\
\text { hour } \\
\text { (R-P) }\end{array}$ \\
\hline & & & $\begin{array}{c}\text { gram per } \\
100 \text { cc. }\end{array}$ & $\begin{array}{c}\text { gram per } \\
100 \mathrm{cc}\end{array}$ & $\begin{array}{l}\text { gram per } \\
100 \text { cc. }\end{array}$ & $\begin{array}{c}\text { gram per } \\
100 \text { cc. }\end{array}$ & $\begin{array}{l}\text { gram per } \\
100 \text { cc. }\end{array}$ \\
\hline 35 & Arteriosclerosis & No & 0.092 & +0.073 & +0.073 & 0.019 & 0.019 \\
\hline 28 & Salvarsan poisoning & No & 0.095 & +0.063 & +0.050 & 0.032 & 0.045 \\
\hline 26 & Lobar pneumonia & No & 0.102 & +0.094 & +0.101 & 0.008 & 0.001 \\
\hline 33 & Lobar pneumonia & Yes & 0.071 & +0.004 & & 0.067 & \\
\hline $1 \mathrm{~A}$ & Cardiac decompensation & No & 0.102 & +0.115 & & & \\
\hline $2 \mathrm{~A}$ & Cerebral hemorrhage & No & 0.064 & +0.085 & & & \\
\hline 43 & Cardiac decompensation & No & 0.134 & +0.133 & +0.105 & 0.001 & 0.029 \\
\hline 27 & Cardiac decompensation & No & 0.102 & +0.076 & +0.103 & 0.026 & \\
\hline 20 & Cirrhosis of liver & No & 0.075 & +0.018 & -0.011 & 0.057 & 0.086 \\
\hline 25 & Gun shot wound of head & Yes & 0.134 & +0.096 & +0.086 & 0.039 & 0.049 \\
\hline 8 & Carbon monoxide poisoning & Yes & 0.066 & +0.027 & & 0.039 & \\
\hline 6 & Fracture of femur & Yes & 0.070 & -0.011 & & 0.086 & \\
\hline 11 & Laceration of liver & Yes & 0.076 & $-0.005 \mid$ & & 0.071 & \\
\hline \multicolumn{6}{|c|}{ 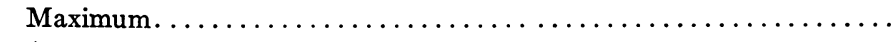 } & 0.086 & 0.086 \\
\hline \multicolumn{6}{|c|}{ Av $\ldots \ldots \ldots \ldots \ldots \ldots \ldots \ldots \ldots \ldots \ldots \ldots \ldots \ldots \ldots$} & 0.032 & 0.032 \\
\hline
\end{tabular}

than that of the plasma, a difference which may be attributed to the concentration of glucose brought about by the elimination of the 
plasma protein. It will also be noted that in every instance the initial rotatory values were considerably below the reducing values of the ultrafiltrates and in one instance the values were levorotatory.

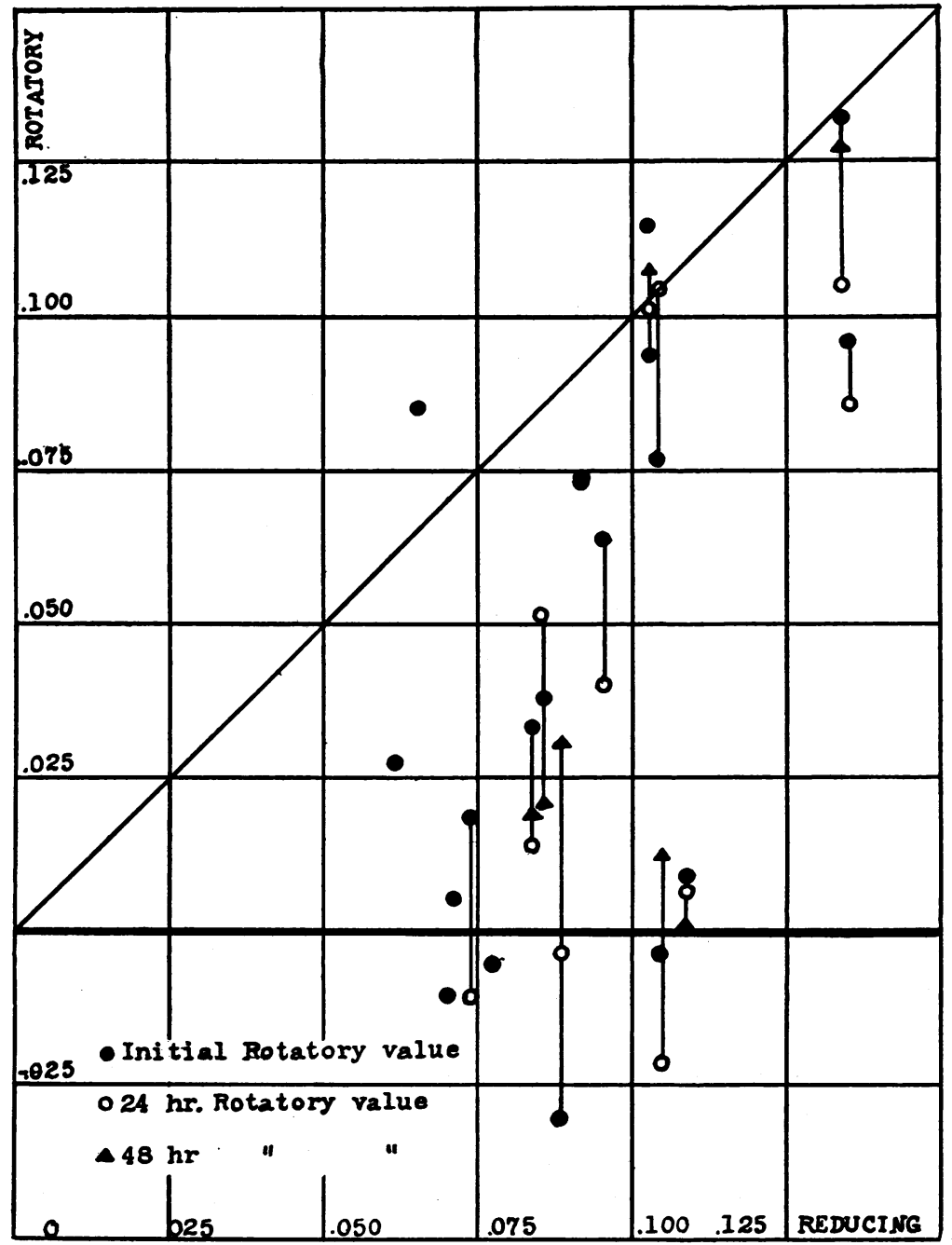

Fig. 2. Reducing and Rotatory Values Encountered in 18 Ultrafiltrates From Normal Individuals aNd Hospital Patients

Daily fluctuations of the rotatory values are charted in 12 instances 
For convenience in the following discussion the difference between the reducing and rotatory value of a specimen, both expressed in terms of grams of glucose per $100 \mathrm{cc}$., will be designated as (R-P). These differences between rotatory and reducing power, (R-P) amounted to between 0.030 and 0.130 gram per $100 \mathrm{cc}$. Rotatory determinations of the ultrafiltrates when made over a period of consecutive days showed in two instances fairly appreciable changes consisting of a forty-eight-hour rise, followed in one instance by a fall, whereas the reducing values remained unchanged. In the others the daily fluctuations were not appreciably beyond the limits of experimental error.

In order to give a general idea of the (R-P) values, a larger series of experiments is shown in table 3 and, together with the six normal values, these are also graphically shown in figure 2 . The results shown in table 3 represent a series of blood samples obtained from general hospital patients in which the blood sugar values, as estimated by copper reduction, ranged between 60 and $135 \mathrm{mgm}$. per $100 \mathrm{cc}$. Diabetic patients or patients with renal lesions showing evidences of nitrogen retention were not included. It will be noted that the (R-P) values showed an initial-maximum value of 0.086 and an average of 0.032 which is not as great as the (R-P) values shown by the series of normal individuals. A study of figure 2 shows the wide extent of the differences between reducing and rotatory values and the irregularity in daily fluctuations which some of the latter exhibit. In two instances the initial rotatory values proved to be greater than the corresponding reducing values. These were the only instances in which this finding was recorded in the course of the entire experimental work totalling more than a hundred such examinations. They have been included in this series, however, in order to emphasize the fact that such values may occur. In 14 of the 18 observations shown in figure 2 the initial rotatory values were considerably lower than the reducing ones. The (R-P) values cover a wide range, the maximum being 0.130 ; and average being about 0.040 . In three instances the initial rotatory values proved to be appreciably levorotatory.

The twenty-four and forty-eight-hour fluctuations of the rotatory values of given ultrafiltrates are charted in several instances. On the whole, these fluctuations, as shown by consecutive readings, have 
been so irregular that it has hardly seemed profitable to present the series in the form of composite curves. In spite of irregularities it may, however, be said that in most cases a rise of the rotatory value of each ultrafiltrate occurred at some time during the first twenty-four or forty-eight hours after the collection and filtration of the blood, following which the values either fell or remained fairly constant.

It may be recalled that Lundsgaard and Holb $\phi 11$ (19) noted that the initial rotatory values in their dialysates from normal blood were consistently lower than the corresponding reducing values, but that these rotatory values rose until at the end of forty-eight hours they agreed with the reducing values so that (R-P) became zero. The present series of experiments corroborates the finding of initial low rotatory values and their occasional tendency to rise; but the eventual agreement of rotatory and reducing values, with (R-P) approximately zero, was observed here in only two instances. It was noted, however, early in the course of these experiments that on hydrolyzing the ultrafiltrates with dilute $\mathrm{HCl}$ the rotatory values frequently rose, whereas the reducing values remained constant or rose very slightly, and the resulting (R-P) values were often greatly diminished and not infrequently were reduced to insignificant values.

\section{GLYCOLYSIS EXPERIMENTS}

In order to investigate the factors which were responsible for the (R-P) values and in an effort to determine whether these values were due primarily to changes in the specific rotation of the plasma glucose or to the presence of optically active substances other than glucose, a series of filtrates was studied in which the glucose had been partially or totally removed. It is evident, of course, that if the plasma glucose can be satisfactorily removed, by a method which does not involve the introduction of new factors one should obtain a rotatory value approximately equal to that of the optically active substances other than glucose which are present in plasma; and one might also expect to obtain the same value for (R-P) both before and after the removal of glucose. If, however, the difference between rotatory and reducing values were due even in part to the fact that the specific rotation of the glucose is lower than the standard value, removal of this glucose should be accompanied by a diminution in the rotatory values which should 
be less than the diminution in the reducing value and (R-P) should diminish with the removal of glucose.

Initially attempts were made to remove the glucose from the blood samples by fermentation with yeast but this method did not prove satisfactory. The procedure which was eventually followed was that of relying on the glycolytic action of whole blood for the removal of sugar. Although this is not a thoroughly satisfactory method it has seemed to be more serviceable than fermentation by yeast.

The procedure followed in this series of experiments consisted in the collection of fairly large samples (100 to $200 \mathrm{cc}$.) of blood in a flask containing crystals of sodium citrate. The sample was divided into

TABLE 4

Reducing and rotatory values before and after glycolysis

\begin{tabular}{|c|c|c|c|c|c|c|c|}
\hline \multirow{3}{*}{$\begin{array}{c}\text { Experiment } \\
\text { number }\end{array}$} & \multicolumn{4}{|c|}{ First portion of blood } & \multicolumn{3}{|c|}{ Second portion-after glycolysis } \\
\hline & \multirow[t]{2}{*}{ Reducing } & \multicolumn{2}{|c|}{ Rotatory } & \multirow[b]{2}{*}{ (R-P) } & \multirow[t]{2}{*}{ Reducing } & \multirow{2}{*}{$\frac{\text { Rotatory }}{24 \text {-hour }}$} & \multirow[b]{2}{*}{ (R-P) } \\
\hline & & Original & 24-hour & & & & \\
\hline & $\begin{array}{l}\text { gram per } \\
100 \text { cc. }\end{array}$ & $\begin{array}{l}\text { gram per } \\
100 \text { cc. }\end{array}$ & $\begin{array}{l}\text { gram per } \\
100 \text { cc. }\end{array}$ & $\begin{array}{l}\text { gram per } \\
100 \text { cc. }\end{array}$ & $\begin{array}{l}\text { gram per } \\
100 \text { cc. }\end{array}$ & $\begin{array}{l}\text { gram per } \\
100 \text { cc. }\end{array}$ & $\begin{array}{l}\text { gram per } \\
100 \text { cc. }\end{array}$ \\
\hline $2 \mathrm{~A}$ & 0.064 & +0.085 & & & 0.014 & -0.022 & 0.036 \\
\hline 26 & 0.102 & +0.094 & +0.101 & 0.001 & 0.038 & -0.011 & 0.048 \\
\hline 33 & 0.071 & +0.004 & -0.001 & 0.072 & 0.020 & -0.076 & 0.096 \\
\hline 35 & 0.092 & +0.073 & +0.073 & 0.019 & 0.020 & -0.013 & 0.033 \\
\hline $0 x^{*}$ & 0.102 & +0.010 & +0.005 & 0.097 & 0.000 & -0.160 & 0.160 \\
\hline
\end{tabular}

* Defibrinated ox blood.

two portions and to the first portion a small amount of sodium fluoride was added to prevent glycolysis and bacterial contamination. This specimen was then centrifuged and an ultrafiltrate obtained from the plasma, of which the rotatory and reducing power was determined. The second portion was allowed to stand either at room temperature or at a temperature of $37^{\circ}$ for a period of twenty-four hours at the end of which time rotatory and reducing determinations were run upon its plasma ultrafiltrate.

The results of a series of 5 experiments carried out as described above on four samples of human blood and on one of ox blood are given in table 4 and are graphically shown in figure 3 . In the first four experiments glycolysis was allowed to proceed at room tem- 
perature and, as a result, the reducing power in the ultrafiltrate, although considerably diminished, was not entirely destroyed. In one instance the initial rotatory value of the ultrafiltrate before glycolysis proved to be levorotatory and in all instances ultrafiltrates

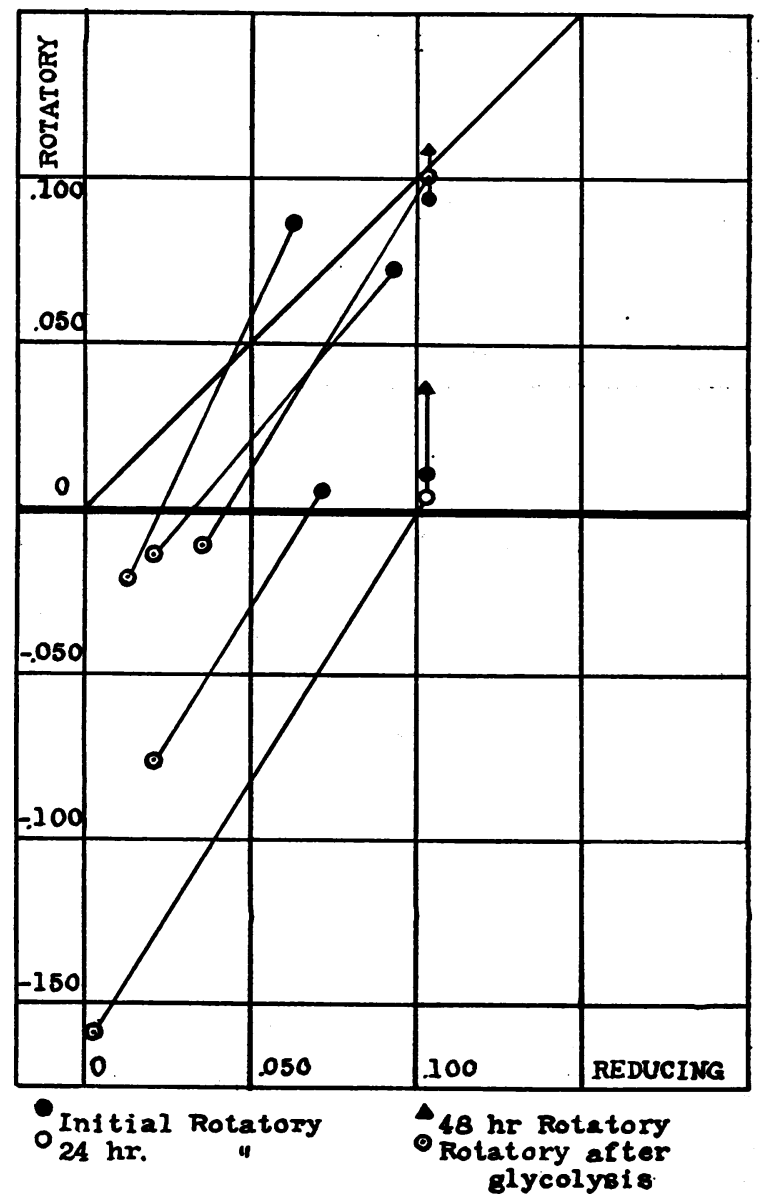

Fig. 3. Reducing and Rotatory Values Before and After Glycolysis

from the glycolyzed specimens on which the reducing values had been diminished to $40 \mathrm{mgm}$. of sugar per $100 \mathrm{cc}$. or below, were levorotatory. The diminution in rotatory value in all instances proved to be either approximately equal to the diminution in the reducing values, if 
calculated on the basis of the standard specific rotation of glucose, or considerably greater. That is, after the removal of glucose (R-P) was unchanged or increased, never diminished.

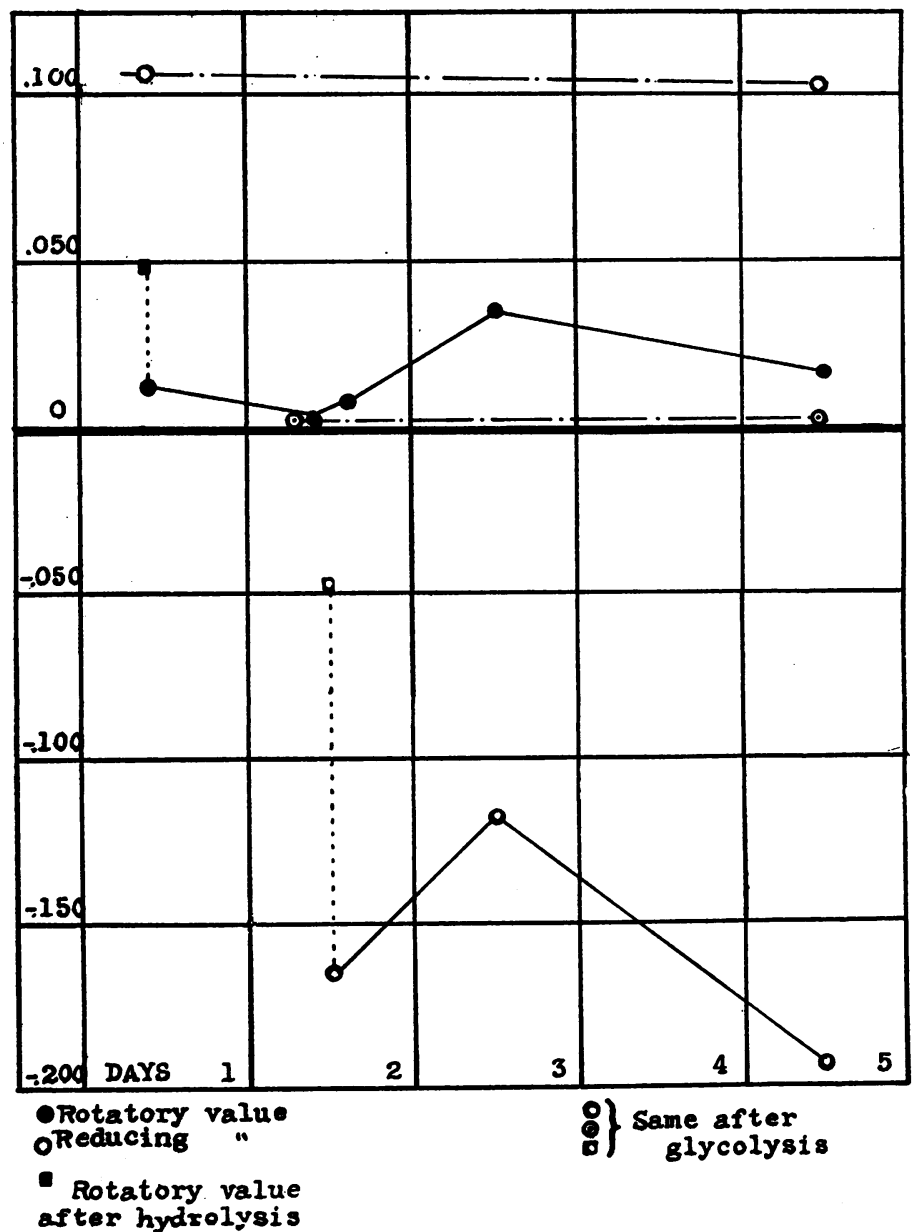

Fig. 4. Rotatory Values on Consecutive Days Before and After Glycolysis

It 'is evident, however, that our interpretation of the results from such an experiment should be guarded, as a number of variable factors complicate the problem. In the first place the relative instability of the rotatory values of ultrafiltrates from the unglycolyzed speci- 
men, as shown by daily fluctuation, renders the accuracy of a comparison with the rotatory values of the glycolyzed specimen somewhat questionable. Furthermore, the results indicate that optically active substances other than glucose are increased or their optical activity is altered during the destruction of the sugar. Lepine (3) has emphasized the fact that if glycolysis of whole blood is allowed to proceed levorotatory substances are increased. The degree to which this variable may influence the results has not been determined, but it is evident that following the glycolytic action of whole blood one does not obtain rotatory values which are similar to the values which might be expected from the simple removal of glucose per se.

TABLE 5

Rotatory values on consecutive days before and after glycolysis

\begin{tabular}{|c|c|c|c|c|c|c|}
\hline & \multirow{2}{*}{$\frac{\text { Reducing }}{\text { Initial }}$} & \multicolumn{4}{|c|}{ Rotatory values } & \multirow{2}{*}{$\begin{array}{l}\text { Reducing } \\
\text { final }\end{array}$} \\
\hline & & Initial & 24-hour & 48-hour & 96-hour & \\
\hline & $\begin{array}{l}\text { gram per } \\
100 \text { cc. }\end{array}$ & $\begin{array}{l}\text { gram per } \\
100 \mathrm{cc} .\end{array}$ & $\begin{array}{l}\text { gram per } \\
100 \mathrm{cc} .\end{array}$ & $\begin{array}{l}\text { gram per } \\
100 \mathrm{cc} .\end{array}$ & $\begin{array}{l}\text { gram per } \\
100 \text { cc. }\end{array}$ & $\begin{array}{l}\text { gram per } \\
100 \mathrm{cc} .\end{array}$ \\
\hline Unglycolyzed specimen. & 0.106 & +0.012 & 0.000 & +0.035 & +0.018 & 0.102 \\
\hline Glycolyzed specimen... & 0.000 & & -0.164 & -0.118 & -0.196 & 0.000 \\
\hline
\end{tabular}

An interesting finding, however, which is graphically shown by a later experiment (fig. 4) was that after hydrolysis of both glycolyzed and unglycolyzed specimens, a comparison of the resulting (R-P) values showed them to be approximately equal. This finding suggests that more than one factor contributes to the difference between reducing and rotatory values, or (R-P) values, and that a certain fraction of this value is due the presence of levorotatory substances which are destroyed or rendered optically inactive on boiling with $\mathrm{HCl}$. It suggests further that the increase in levorotation after glycolysis represents essentially an increase of this fraction of relatively unstable levorotatory substances.

Although the method of removing glucose by means of the glycolytic action of whole blood is open to criticism, it was felt that a study of the daily fluctuations of rotatory values after glycolysis might be of significance.

This experiment was performed on a sample of defibrinated ox 
blood, following the procedure utilized in the previous glycolysis experiments. The ultrafiltrates from both the original and the glycolyzed specimen were kept for several days and readings of each were obtained at intervals during this period. The results are shown in table 5 and figure 4 .

The fluctuations exhibited by the rotatory values of the original unglycolyzed ultrafiltrate showed little change in the first twentyfour hours, followed by a moderate rise in the forty-eight-hour reading and a subsequent fall to the original value in ninety-six hours. In the glycolyzed specimen also the forty-eight-hour reading showed a sharp rise followed by an abrupt fall at the end of ninety-six hours. The experiment proved clearly that if sugar is removed from the blood by the glycolytic action of blood cells and the rotatory values of this sugar free ultrafiltrate is studied over a period of four days definite fluctuations in these values are recorded which show an approximate, although not an exact, parallelism to similar daily fluctuations of the rotatory readings from the original unglycolyzed specimen.

\section{SUMMARY}

In a series of comparative studies of the rotatory and reducing values of 18 ultrafiltrates from blood plasma of normal individuals and general hospital patients, exclusive of diabetics and nephritics, it was found that initially (i.e., twenty-four hours after collection of the sample) agreement of the rotatory and reducing values was recorded in only two instances. In the others rather wide irregular differences were noted, which have been designated in these experiments as (R-P) values and, if expressed in terms of glucose, these values were found to range between 0.010 and 0.130 gram per $100 \mathrm{cc}$., averaging about 0.040 gram per $100 \mathrm{cc}$. Occasionally the initial rotatory values proved to be levorotatory. In studying the rotatory values of the same ultrafiltrate over a period of consecutive days definite fluctuations were noted, whereas the reducing values remained unchanged. These fluctuations of the rotatory values were distinctly irregular but generally showed a tendency to rise at some time during the first fortyeight hours, after which time there was either a subsequent fall or little if any change. In two instances the rotatory values rose on standing 
to equal the reducing values. On hydrolyzing the ultrafiltrates it was found that the (R-P) values were often very appreciably diminished and in some instances became zero. In ultrafiltrates made after the blood sugar had been partially or wholly removed through the glycolytic action of whole blood the rotatory values became levorotatory, the difference between reducing and rotatory values being either equal to, or greater than that noted in an ultrafiltrate from the same blood before glycolysis. However, after hydrolysis of both glycolyzed and unglycolyzed specimens, a comparison of the (R-P) values showed them to be approximately equal.

Another interesting finding proved to be that, if the rotatory values of an ultrafiltrate from these glycolyzed specimens were studied over a period of consecutive days, pronounced fluctuations were observed which were similar to the fluctuations of the rotatory values occurring in the ultrafiltrate from an unglycolyzed sample of the same blood.

In general, therefore, the findings show that levorotatory substances (which may or may not have slight reducing power) are normally present in blood. It has been shown that this levorotation is decreased on hydrolysis and generally increased if the glycolytic action of whole blood has been allowed to proceed. There is further suggestive evidence which is not, however, conclusive, that the relative instability and daily fluctuations exhibited by these levorotatory substances on standing are responsible for the somewhat similar fluctuations of the rotatory values which have been noted so frequently in normal blood; an interpretation which has been given by many other investigators, notably Visccher (18) and Macleod (15).

In considering how far the evidence presented by these experiments is in accord with theories which suggest that part of the glucose present in blood is of lower specific rotation than $\alpha, \beta$-glucose, it is clear that one cannot explain the entire (R-P) value on such a basis. The results furnish evidence of the presence of relatively unstable levorotatory substances which probably have little or no reducing power but no evidence of the presence of substances presenting the properties either of $\gamma$-glucose or the "new glucose" of Lundsgaard and Holbøll. They do not exclude the existence of such substancês which might be present together with $\alpha, \beta$-glucose and the levorotatory 
substances noted above, but they suggest another explanation of the observed phenomena without postulating the presence of $\gamma$-glucose or "new glucose."

It is not within the scope of this paper to discuss the nature of the levorotatory substances which have been referred to above. Such substances might include conjugated glucuronic acids, amino and fatty acids, etc., but in all probability one of the chief levorotatory substances is conjugated glucuronic acid which has been demonstrated in the blood of normal human beings and animals by Mayer (2), Lepine (3), and Stepp (11). The presence of glucuronic acid in urine is well recognized as being largely responsible for the levorotatory values of normal urine, and these rotatory values have also been shown to exhibit definite fluctuations on standing (25).

In conclusion I wish to express my appreciation to Miss E. F. Herr for assistance in the analytical work and to Dr. J. H. Austin for his helpful criticism during the course of the experiments.

\section{CONCLUSIONS}

The evidence brought forward by these experiments confirms the presence, often noted by others, of levorotatory substances in normal blood and suggests that changes in these optically active substances other than glucose, whatever their nature may be, are largely responsible for the fluctuations of the rotatory values observed under the conditions of these experiments in ultrafiltrates from plasma.

\section{BIBLIOGRAPHY}

1. Hiller, A., Linder, G. C., and Van Slyke, D. D.: Jour. Biol. Chem., 1925, Ixiv, 625. The Reducing Substances of the Blood.

2. Mayer, P.: Zeit. Physiol. Chem., 1901, xxxii, 518. Uber eine bisher unbekannte reducirende Substanz des Blutes.

3. Lepine, R., and Boulud: Compt. rend. des. Sc. de l'Acad. d. Sci., 1901, cxxxiii, 720. Physiologie. Sur les Sucres du Sange et leur Glycolyse.

Lepine, R., and Boulud: Compt. rend. des Sc. de l'Acad. d. Sci., 1902, cxxxiv, 398. Chimie Animale. Sur le Dosage des Sucres dans le Sang.

Lepine, R., and Boulud: Compt. rend. des Sc. de l'Acad. d. Sci, 1902, cxxxv, 139. Chimie. Animale. Sur l'Acide Glycuronique dans le Sang du Chien.

4. Michaelis, L., and Rona, P.: Biochem. Zeit., 1908, xiv, 476. Untersuchungen über den Blutzucker. IV. Die Methode der osmotichen Kompensation. 
5. Rona, P., and Takahashi, D.: Biochem. Zeit., 1910, $x \times x, 99$. Untersuchungen über den Blutzucker. VIII. Utber den Zuckergehalt der Blutkorperchen.

6. Oppler, B.: Zeit. Physiol. Chem., 1910, lxiv, 393. Zur Methodik der quantitativen Traubenzuckerbestimmung des Blutes.

Oppler, B.: Zeit. Physiol. Chem., 1911, lxxv, 71. Die Bestimmung des Traubenzuckers in Harn und Blut.

7. Lyttkens, H., and Sandgren, J.: Biochem. Zeit., 1911, xxxi, 153. Utber die Verteilung der reduzierenden Substanzen im Menschenblut.

8. Griesbach, W., and Strassner, H.: Zeit. Physiol. Chem., 1913, lxxuviii, 199. Zur Methodik der Blutzucker Bestimmung.

9. Maase, C., and Tachau, H.: Zeit. f. klin. med., 1915, lxxxi, 1. Vergleichende Blutzuckerbestimmungen durch Polarisation und Reduktionsmethoden.

10. Stepp, W.: Zeit. Physiol. Chem., 1919, cvii, 29. Beitrage zur Kenntniss der reduzierenden Substanzen des Blutes.

Stepp, W.: Arch. f. exp. Path. u. Pharm., 1921, xc, 105. Kritisch-analytische Betrachtungen und Untersuchungen zur Bestimmung des wahren Blutzuckers bein Gesunden und Kranken.

Stepp, W.: Ergebn. Physiol., 1922, xx, 108. Über einige den Blutzucker betreffende Fragen im Lichte neuren Forschungsergebnisse.

11. Stepp, W.: Zeit. Physiol. Chem., 1919, cvii, 264. Über des Vorkommen von Glukuronsäure im Menschlichen Blute.

12. Winter, L. B., and Smith, W.: Jour. Physiol., 1923, lvii, 100. On the Nature of the Sugar in the Blood.

Forrest, W. D., Smith, W., and Winter, L. B.: Jour. Physiol., 1923, lvii, 224.

On the Change in the Nature of the Blood Sugar of Diabetics Caused by Insulin.

13. Hewitt, J. A.: Brit. Med. Jour., 1923, i, 590. Nature of Sugar in Blood.

14. Eadie, G. S.: Brit. Med. Jour., 1923, ii, 60. Behavior of Blood Sugar under Action of Insulin and Other Agents.

15. Macleod, J. J. R.: Physiol. Rev., 1924, iv, 21. Insulin.

16. Van Creveld, S.: Biochem. Jour., 1923, xvii, 860. Some experiments and Remarks on the Possible Transformation of d-Glucose in the Intestine and on the Nature of Blood Sugar.

17. Denis, W., and Hume, H. V.: Jour. Biol. Chem., 1924, 1x,603. On the Nature of Blood Sugar.

18. Visscher, M. B.: Amer. Jour. Physiol., 1926, lxxvi, 59. A Critical Study of the Evidence for the Presence of an Isomer of d-Glucose in Blood.

19. Lundsgaard, C., and Holbøll, S. A.: Jour. Biol. Chem., 1925, lxv, 323 and 343. Studies in Carbohydrate Metabolism. III and IV.

20. Lundsgaard, C., and Holbøll, S. A.: Jour. Biol. Chem., 1924, lxii, 453. Effect of Insulin and Muscle Tissue on Glucose in Vitro.

Lundsgaard, C., and Holbøll, S. A.: Jour. Biol. Chem., 1925, lxv, 305. Studies in Carbohydrate Metabolism. II. 
21. Eggerth, A. H.: Jour. Biol. Chem., 1921, xlviii, 203. The Preparation and Standardization of Collodion Membranes.

22. Marshall, E. K., and Vickers, J. L.: Bull. Johns Hopkins Hosp., 1923, xxxiv, 1. The Mechanism of the Elimination of Phenolsulphonephthalein by the Kidney. A Proof of Secretion by the Convoluted Tubules.

23. Folin, O., and Wu, H.: Jour. Biol. Chem., 1919, xxxviii, 81. A System of Blood Analysis.

Folin, O., and Wu, H.: Jour. Biol. Chem., 1920, xli, 367. A System of Blood Analysis. Supplement 1.

24. Host, H. F., and Hatlehol, R.: Jour. Biol. Chem., 1920, xlii, 347. Blood Sugar Concentration and Blood Sugar Methods.

25. Paul, J. R.: Jour. Clin. Invest., 1925, i, 317. The Optical Activity of Glucose as Influenced by Normal and Diabetic Urine.

26. Anderson, A. B., and Carruthers, A.: Biochem. Jour., 1926, xx, 556. Studies in Carbohydrate Metabolism. I. The Relation Between Optical Activity and Reducing Power of Normal Blood Filtrates, Interaction of Muscle Tissue, Insulin and Glucose. 